\title{
Alternativas de Utilização de Resíduos sólidos alcalinos NA DISPOSIÇÃO DE RESÍDUOS CONTAMINADOS: ESTUDO DE caso no estado do Rio de Janeiro, Brasil
}

\author{
ALKALINE RESIDUES ALTERNATIVES FOR USE IN THE LANDFILL OF A \\ CONTAMINATED SOLID RESIDUES: CASE STUdY FROM RIO DE JANEIRO, BRAZIL
}

\section{Wilma de Carvalho Pereira}

DSc. em Geoquímica pela Universidade Central de Barcelona - UCB, Espanha. Pesquisadora do Departamento de Saneamento e Saúde Ambiental da Escola Nacional de Saúde Pública - Fundação Oswaldo Cruz (ENSP/FIOCRUZ)

\section{DALTON MARCONDES E SILVA}

DSc. em Saúde Pública pela Escola Nacional de Saúde Pública/Fundação Oswaldo Cruz - ENSP/FIOCRUZ. Pesquisador do Departamento de Saneamento e Saúde Ambiental da ENSP/FIOCRUZ

\section{JUREMI DE Oliveira Carvalho}

Especialista em Engenharia Sanitária e do Meio-ambiente pela Universidade do Estado do Rio de Janeiro - UERJ. Pesquisador do Departamento de Saneamento e Saúde Ambiental da Escola Nacional de Saúde Pública (ENSP/FIOCRUZ).

\section{NeLSON Moura BRASIL do Amaral SOBRINHo}

DSc. em Agronomia (Solos e Nutrição de Plantas) pela Universidade Federal de Viçosa, Minas Gerais. Professor do Instituto de Agronomia da Universidade Federal Rural do Rio de Janeiro - UFRRJ

\section{ALEXANDRE RAVELLI NETO}

DSc. em Agronomia (Ciências do Solo) pela Universatà Degli Studi Di Firenze, Florença. Itália. Professor da do Instituto de Agronomia da Universidade Federal Rural do Rio de Janeiro - UFRRJ

\section{Roberto CerRini VilLas BôAS}

PhD. em Engenharia de Materiais pela Colorado School of Mines, U.S.A. Pesquisador do Centro de Tecnologia Mineral - CETEM

\author{
Recebido: 22/01/07 Aceito: 10/04/08
}

\section{RESUMO}

Este trabalho tem como objetivo o estudo dos elementos potencialmente contaminantes presentes nos rejeitos industriais que são dispostos no meio ambiente e, por processo de lixiviação, carreados para os corpos hídricos. Dois tipos de resíduos foram estudados. Um deles, proveniente da indústria de produção de aço (escória da aciaria), de características alcalina. Este rejeito é considerado relativamente estável pelos padróes vigentes devido às suas características $(\mathrm{Cd}<0.5 \mathrm{mg} / \mathrm{Kg}$, $\mathrm{Pb}<10 \mathrm{mg} / \mathrm{Kg}, \mathrm{Co}<5 \mathrm{mg} / \mathrm{Kg}, \mathrm{Cu}=61 \mathrm{mg} / \mathrm{Kg}, \mathrm{Ni}<1.5 \mathrm{mg} / \mathrm{Kg}$, $\mathrm{Zn}=75 \mathrm{mg} / \mathrm{Kg}$ ). No entanto, até o momento, não existe uma alternativa para a sua total utilização. O outro resíduo, oriundo de um passivo ambiental, de uma indústria de galvanoplastia (Classe I: ABNT, 1987), cerrada oficialmente em 1998.

\section{ABSTRACT}

The goal of this work is to study the potentially contaminating trace elements present in industrial waste that is discharged into the environment though lixiviation process to water resources. Two types of waste were studied. The first one, a refuse slag from steel industry, an alkaline residue. Even though this waste is considered relatively stable within the established standards set by current legislation due to its characteristics $(C d<0.5 \mathrm{mg} / \mathrm{Kg}$, $\mathrm{Pb}<10 \mathrm{mg} / \mathrm{Kg}, \mathrm{Co}<5 \mathrm{mg} / \mathrm{Kg}, \mathrm{Cu}=61 \mathrm{mg} / \mathrm{Kg}, \mathrm{Ni}<1.5 \mathrm{mg} / \mathrm{Kg}$, $Z n=75 \mathrm{mg} / \mathrm{Kg}$ ), there is so far no feasible alternative for its total reutilization. The other one a residue from the electroplating industry (Class I: ABNT, 1987), closed down in 1998. 


\section{INTRODUÇÃO}

No Brasil, o gerenciamento adequado dos resíduos sólidos industriais constitui um grande desafio. Atualmente um dos grandes problemas enfrentados pela engenharia ambiental é a destinação de tais materiais. Dentre as alternativas existentes, a disposição dos resíduos é a efetivamente praticada pelas indústrias de grande porte, devido às grandes quantidades de materiais gerados nos processos. A reutilização é também considerada, em muitos casos, para diversos fins, como pavimentação de estradas, incorporação à massa de cimento na construção civil, incorporação ao solo, etc. Em todos os casos, tanto para a reutilização, quanto para a disposição, temos que levar em consideração os elementos potencialmente contaminantes que podem ser introduzidos no meio circundante.

A Baía de Sepetiba pertence ao litoral brasileiro do Estado do Rio de Janeiro (2300'27.27"S, 4350'19.60"O). Nela se situam a Restinga de Marambaia, que a delimita ao Oceano Atlântico. A Baía de Sepetiba, é um corpo de águas salinas e salobras, que se comunica com o oceano. A cada ano, as águas da Baía de Sepetiba, recebem 1,2 milhões de metros cúbicos de sedimentos. O lixo, o esgoto e os contaminantes oriundos de rejeitos industriais vêm provocando o assoreamento dos corpos hídricos da região. Em comparação com os outros setores, o setor metalúrgico é o de maior relevância, tanto em função da quantidade do material quanto na poluição das águas e sedimentos da Baía de Sepetiba, com o lançamento de efluentes líquidos e resíduos tóxicos sem o devido tratamento (Torres, 2003).

Localizada no município de Itaguaí, Ilha da Madeira, a Cia. Mercantil Ingá, que tinha como principal atividade a produção de zinco de alta pureza, representa ainda o maior risco potencial de agressão ao ecossistema da região. Seus estoques de resíduos, acumulados durante todos estes anos, contaminaram e ainda ameaçam e fragilizam o equilíbrio ecológico da Baía de Sepetiba. Hoje, a Ingá, encontra-se sob intervenção Federal, o que limita a atuação do Estado (FEEMA, 2008).

A Companhia Mercantil e Industrial Ingá foi condenada em processo movido pela justiça, em novembro de 2000, por contaminação da água com metais pesados lançados na Baía de
Sepetiba. A empresa deveria, segundo as exigências judiciais, construir um aterro industrial e remover, em sessenta dias, os três milhões de toneladas de resíduos químicos deixado na Ilha da Madeira, em Itaguaí, o que não ocorreu até os dias de hoje. O cádmio, mesmo em concentrações baixas, além de ser altamente tóxico para determinadas espécies aquáticas, tem efeitos sobre o organismo humano, podendo se acumular lentamente em vários tecidos do corpo como os ossos, fígado, rins, pâncreas e tireóide. $\mathrm{O}$ zinco é cumulativo e causa sérios problemas na fisiologia, principalmente dos peixes, tornando-os impróprios para o consumo. O chumbo, também cumulativo, no sangue, está associado aos eritrócitos, sendo em seguida distribuído aos tecidos moles (maiores concentrações no fígado e rins) e aos minerais (ossos e dentes). Devido a este problema, há a necessidade de se desenvolverem mecanismos em busca de soluções que possam minimizar os impactos decorrentes da disposição deste resíduo e, ao mesmo tempo, procurar reduzir os custos envolvidos nessa atividade.

Desta forma, no presente estudo, o material contaminado em foco foi o resíduo proveniente do passivo ambiental da Companhia Mercantil e Industrial Ingá, que encerrou suas atividades há mais de 20 anos, tendo, no entanto, decretado falência oficialmente somente em 1998. Trata-se de uma proposta para a solução de problemas causados pelo acúmulo de rejeitos contendo metais pesados, principalmente cádmio, chumbo e zinco, resultantes das operaçôes da Companhia. Foram estudados também os resíduos da Cia. Siderúrgica Nacional - CSN, que foram empregados como inertizante no processo experimental realizado no presente trabalho, devido a sua alta alcalinidade. Trata-se de resíduo produzido pelo conversor, no processo de produção do aço. Para que este objetivo seja factível na prática, já existe uma infra-estrutura de escoamento de matérias primas e produtos da CSN para a região do Porto de Sepetiba, o que motivou o estudo ora realizado. $\mathrm{Na}$ Figura 1 pode ser observado um pátio de minérios, utilizado pela CSN. Este transporte de material é realizado através de ferrovia.

Para estudos de disposição de resíduos, como o proposto, naturalmente, é necessário o conhecimento de cada tipo de material em particular, Portanto, este trabalho se baseou no estudo das características e propriedades dos resíduos; e a disponibilidade de materiais sorventes, a fim de elucidar os parâmetros necessários à sua utilização no controle de efluentes líquidos, provenientes da percolação dos resíduos potencialmente tóxicos. Os argilominerais vêm sendo muito estudados para o emprego proposto, ou seja, de atenuação da mobilidade de elementos potencialmente contaminantes, devido às propriedades que apresentam, tais como: a) versatilidade de troca catiônica, possibilitando a introdução de uma variedade de íons entre as suas camadas, b) capacidade de inchamento, acomodando um grande número de compostos entre as camadas, e c) capacidade de ser exfoliada e depois reagrupada sem ocorrer mudanças na estrutura cristalina, de acordo com Santos (1992).

Para este estudo, foram analisados, primeiramente, os materiais a serem utilizados como sorvente e foi escolhido um argilomineral do grupo da esmectita para dar partida ao experimento. Foram estudadas as propriedades físicas e químicas, área superficial e composição mineralógica dos materiais, de acordo com as características e função no processo. Os resíduos, naturalmente, foram analisados em função do conhecimento do seu potencial contaminante. Os resíduos da Cia. Siderúrgica Nacional estão localizados na cidade de Volta Redonda, Estado do Rio de Janeiro, figura 2. Os resíduos da Ingá, passivo ambiental da Indústria de Galvanoplastia, que pode ser observado nas Figuras 3 e 4, estão localizados quase imediatamente atrás do porto de Sepetiba.

\section{Localização da área}

A área estudada pertence à Ilha da Madeira, Itaguaí, Rio de Janeiro (figura 1 e 3 ), com as coordenadas geográficas 22 $2^{\circ} 54^{\prime} 53.81^{\prime \prime}$ de latitude sul e 4349'39.76" de longitude oeste. Trata-se de uma região litorânea, conforme pode ser observado na Figura 3. Está inserida no ecossistema da Baia de Sepetiba. Praticamente toda a região litorânea do Brasil estava coberta por floresta tropical (Mata Atlântica), que originalmente cobria cerca de $1.100,000 \mathrm{Km}^{2}$ e atualmente está reduzida a cerca de $7.5 \%$ da área total (Myers et al., 2000). A região onde se localiza a Baía de Sepetiba compreende diferentes tipos de vegetação, além da 
remanescente da Mata Atlântica, como restingas e mangues. É quente e úmida, com temperaturas elevadas e altos índices pluviométricos, principalmente no verão, entre dezembro e março; e seco, com temperaturas mais amenas, no inverno (junho-agosto).

\section{METODOLOGIA}

\section{Amostragem}

Os trabalhos de campo constaram essencialmente de coleta das amostras do passivo ambiental da Ingá. Procurando selecionar pontos de amostragem representativos, foram efetuadas as coletas ao longo de todo o passivo, em amostras simples do topo, meio e base da pilha do resíduo, formando uma amostra composta de aproximadamente $1 \mathrm{~kg}$ (ABNT, 1987). No laboratório a amostra do resíduo foi seca ao ar, destorroada, passada por peneiras e acondicionada. As amostras da escória do conversor foram cedidas pela Companhia Siderúrgica Nacional - CSN. As amostras foram submetidas a etapas de preparação que envolveu a cominuição, homogeneização e quarteamento. A determinação da área superficial e o estudo da porosidade do material foram realizados utilizando o Accelerated Surface Area and Porosimetry System - ASAP, Micromeritcs, 2010, utilizando a técnica de adsorção / desorção de nitrogênio. A análises mineralógicas foram efetuadas no Centro de Tecnologia Mineral (CETEM), empregando um SEM/XDS (Scanning Electron Microscopy/X-ray Dispersive Spectroscopy) LEO $\$ 440$, equipado com um sistema de microanálise por dispersão de energia Link ISIS L300 com detector SiLi Pentafet, janela ultra fina ATW II, de resolução de $133 \mathrm{eV}$ para $5,9 \mathrm{keV}$. As análises foram efetuadas com $20 \mathrm{kV}$ de tensão de aceleração de elétrons. Foram utilizados para a determinação da composição mineralógica, um difratômetro de Raios X (XRD), Siemens AXS, D505 e a técnica de fluorescência de Raios X (Phillips, modelo TW2400), para a análise dos compostos. Foram realizados teste de condutividade hidráulica, utilizando um permeâmetro. Os elementos metálicos dos materiais (resíduos e argilominerais), além do efluente líquido percolado, foram analisados com o espectrômetro de absorção atômica Spectr AA - 600 Varian.

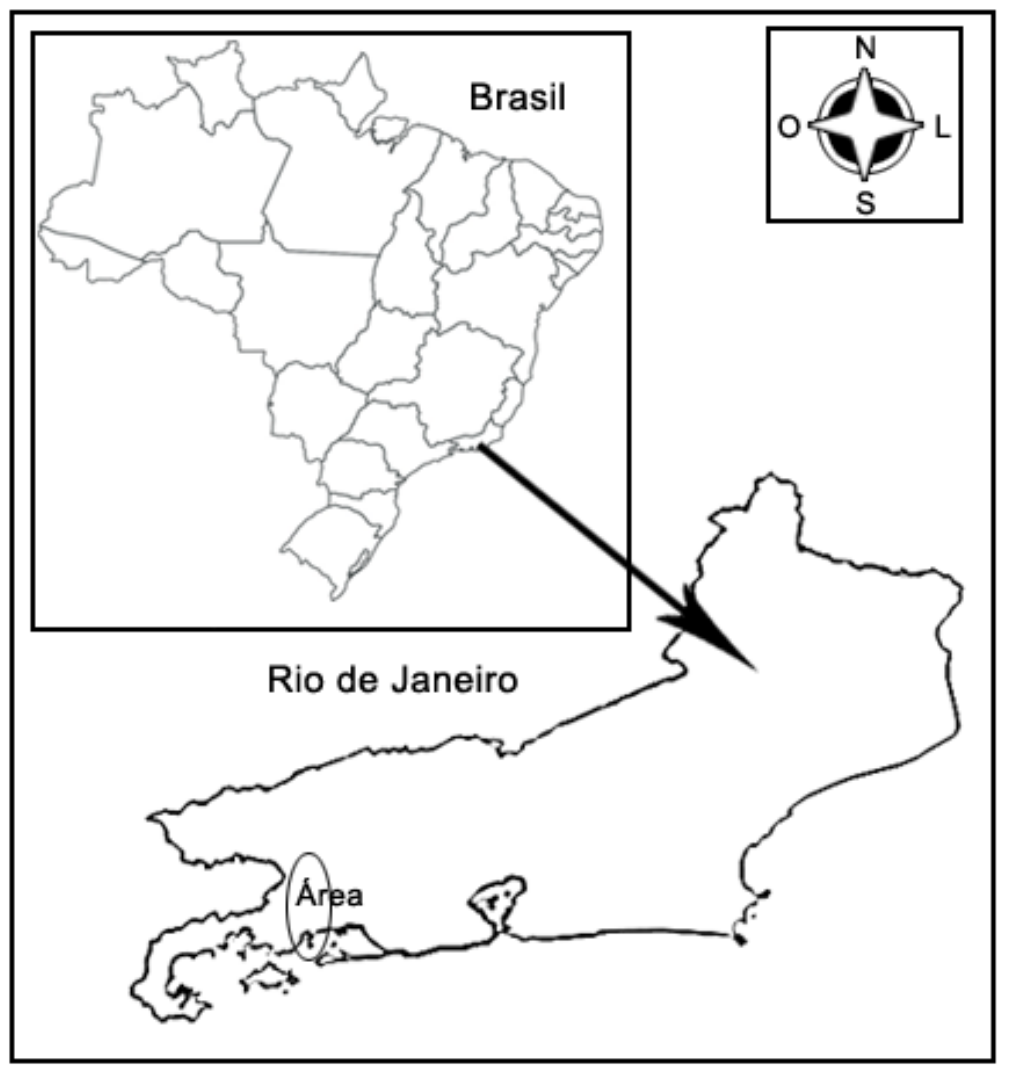

Figura I- Área do projeto em estudo

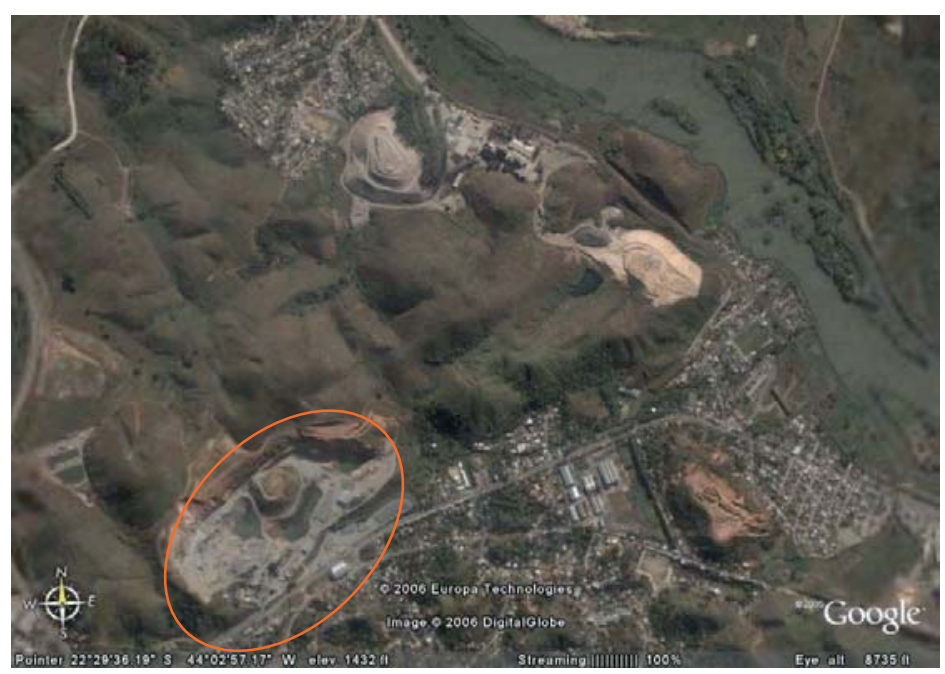

Fonte: Google Earth

Figura 2 - Parque de resíduos da Cia. Siderúrgica Nacional - CSN 


\section{Aparato experimental}

Os testes foram realizados em um aparato experimental em escala de bancada, que consiste em célula de acrílico transparente, recheada com os resíduos indicados e o argilomineral do grupo da esmectita, utilizado como adsorvente; $\mathrm{e}$ ainda um material composto de grãos de quartzo, inerte ao processo; filtro e frascos para captação do percolado, além de recipientes para armazenagem de água acidificada ( $\mathrm{pH} 4$ a 4,5). O afluente líquido acidificado (simulando água de precipitação pluviométrica) foi bombeado através de mangueiras para as células, passando então pelo material acamado, sendo coletado em frascos, para posterior análise. $\mathrm{O} \mathrm{pH}$ foi definido, em função da média apresentada em precipitaçôes pluviométricas em regiōes de industrialização pesada (siderurgia, termoelétrica, etc.).

\section{RESULTADOS E DISCUSSÃO}

A partir do início do experimento foi observado o começo de gotejamento seis dias após, mantendo-se uma lâmina de água de $5 \mathrm{~cm}$, sendo que no decorrer do mesmo houve uma cimentação, tendo cessado o escoamento aproximadamente 62 (sessenta e dois) dias após. A Figura 5 mostra a montagem experimental simulando, em escala de laboratório, as possibilidades de disposição em aterro industrial, que são: o argilomineral na base como mostra a Figura 5 em C2 e C3, ou disposta entre o resíduo da CSN e o da Ingá, como C1.

A composição química do argilomineral estudado foi obtida empregando a técnica de fluorescência de raios X, para a determinação dos compostos presentes. A tabela 1 apresenta os resultados obtidos. Os resultados apresentados pelo equipamento de difração de raios X, figura 6 , mostram linhas de interferência basais no grupo da montmorilonita, e do grupo da caulinita. Apresentou também bandas que indicam a presença de argilomineirais de camadas mistas ilita-montmorilonita, irregularmente interestratificadas, conforme podemos observar nos difratogramas apresentados na Figura 6. $\mathrm{O}$ quartzo está presente em pequenas proporções.

A esmectita estudada é policatiônica, apresentando um pequeno incha-

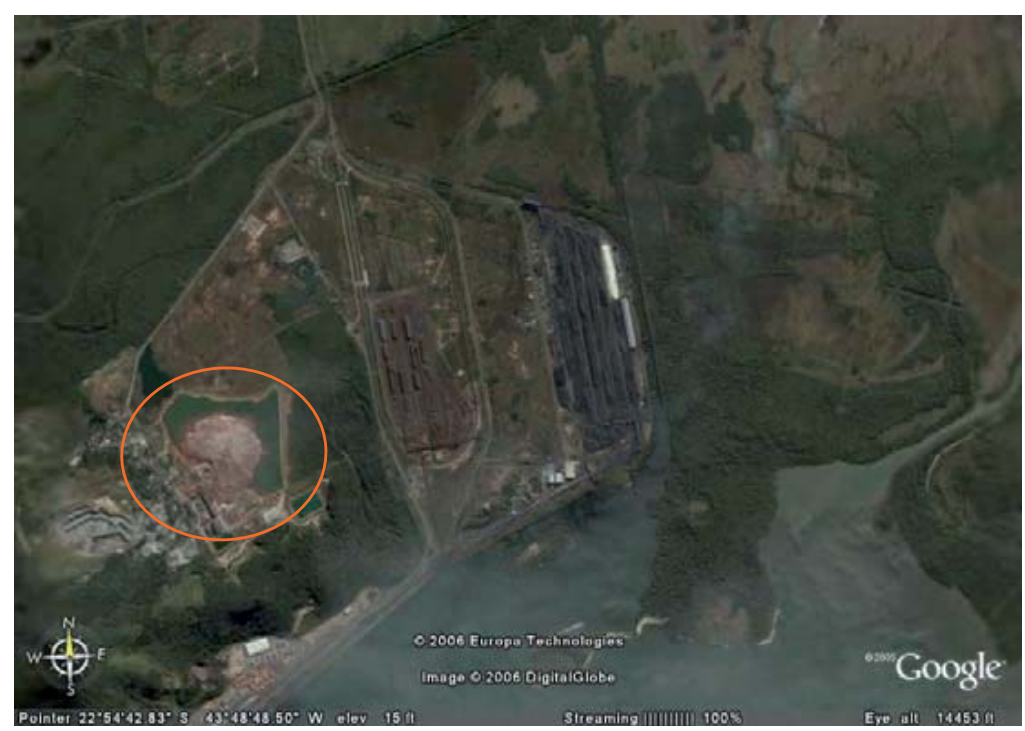

Fonte:Google Earth

Figura 3 - Passivo ambiental da Cia. de Galvanoplastia Ingá

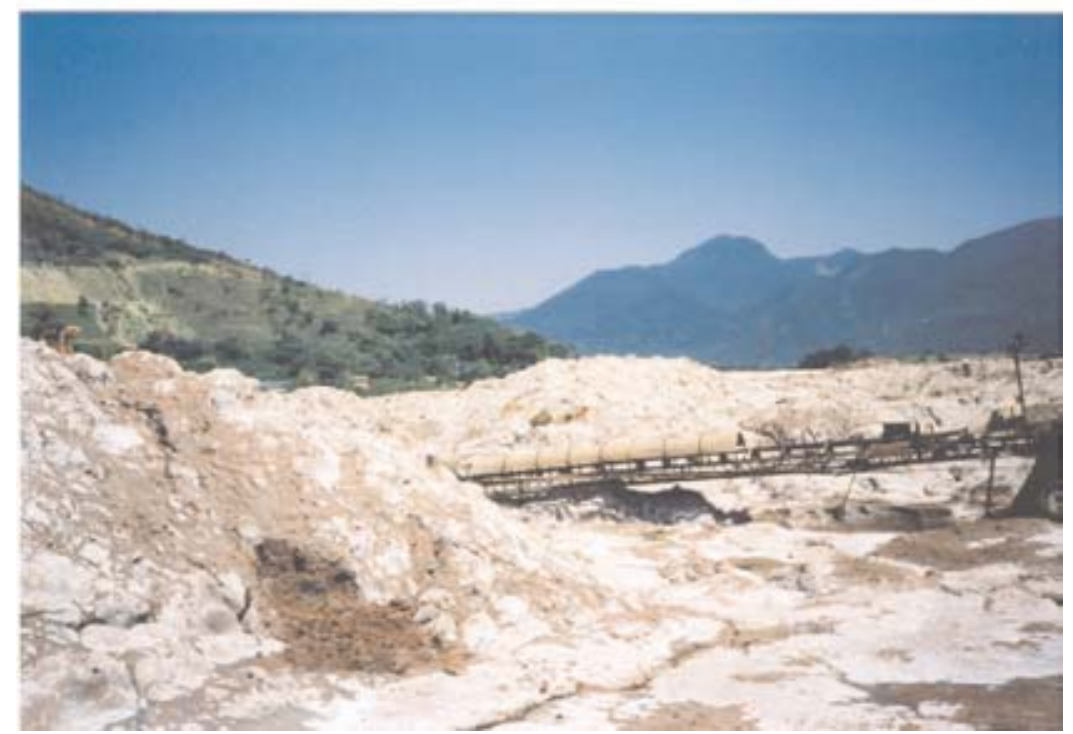

Figura 4 - Passivo ambiental da Cia. de Galvanoplastia Ingá, mostrando um dos pontos de coleta de amostra

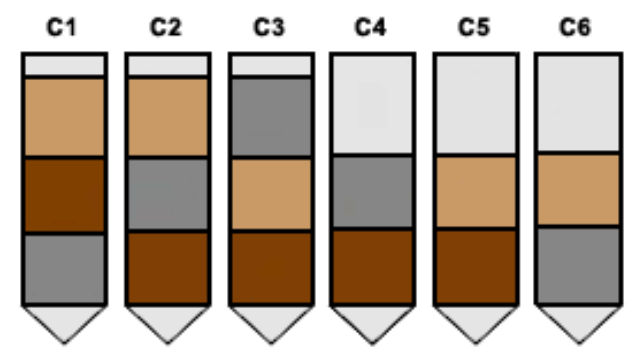

Legenda:

$\square$ Escória de aciaria

$\square$ Resíduo de Ingé

Argilomineral

Figura 5 - Esquema experimental da disposição de acamamento das amostras estudadas. Células de acrílico transparentes com dimensões aproximadas de $24 \mathrm{~cm}$ de altura e $10 \mathrm{~cm}$ de largura 
mento. Esta capacidade de inchamento do argilomineral pode proporcionar um efeito positivo, como indicado anteriormente, promovendo uma retenção de compostos e, possivelmente, com isso, também de elementos deletérios. Essa característica apresentada pelo grupo das esmectitas, age também como um retardador do escoamento do líquido afluente pela redução da permeabilidade, muito benéfica para o processo, como veremos na seqüência do trabalho.

Foi realizado o teste de condutividade hidráulica, de acordo com a equação de Darcy (1). O valor da condutividade hidráulica foi medido através de um permeâmetro do tipo "coluna d'água de altura constante". Os resultados obtidos foram de $2,19 \times 10^{-4} \mathrm{~cm} / \mathrm{s}$ para os resíduos da INGA e $10^{-3} \mathrm{~cm} / \mathrm{s}$ para a escória de aciaria da CSN. Para a amostra do argilomineral, no tempo de escoamento requisitado, conforme metodologia (Forsythe, 1975), não houve qualquer escoamento do líquido afluente, o que sugere muito baixa condutividade hidráulica. A condutividade hidráulica tem um papel fundamental no processo, pois quanto mais veloz o fluxo, menor a possibilidade de retenção de compostos. No entanto, no resultado de porosimetria, a área BET encontrada foi de $68,88 \mathrm{~m}^{2} / \mathrm{g}$, com a relação $\mathrm{P} / \mathrm{P}_{0}$ 0,12092031 de $67,92 \mathrm{~m}^{2} / \mathrm{g}$. Estes resultados indicam características adequadas para uma possível adsorção nas estruturas do argilomineral em questão.

$\mathrm{q}=-\mathrm{K}(\mathrm{DWB}-\mathrm{D}\} \mathrm{A}) / \mathrm{DZ}$

Onde:

$\mathrm{Q}=$ fluxo de água $(\mathrm{cm} / \mathrm{s})$

$-\mathrm{K}$ = condutividade hidráulica $(\mathrm{cm} / \mathrm{s})$

$\Psi_{\mathrm{p}}=$ potencial de pressão

$\psi_{\mathrm{g}}=$ potencial gravitacional

$\Delta \mathrm{Z}=$ distância percorrida pelo líquido

Conforme já mencionado, o percolado foi analisado através da técnica de absorção atômica, e os resultados são apresentados na tabela 2 . O número de elementos analisados com esta técnica não pôde ser grande, no entanto, teve-se a oportunidade de avaliar os elementos de maior relevância. As corridas, apresentadas no índice da Tabela 2, se referem a cada $500 \mathrm{~mL}$ de líquidos afluentes às células do experimento. Os valores obtidos foram estudados em comparação às referências normativas Resolução CONAMA 357/2005. Foram utilizados para o estudo os valores de lançamento de efluentes.
Tabela I - Composição química do argilomineral estudado obtida empregando a técnica de fluorescência de raios $X$

\begin{tabular}{cc}
\hline Compostos & Argilomineral (\%) \\
\hline $\mathrm{CaO}$ & 0,79 \\
$\mathrm{MgO}$ & 2,2 \\
$\mathrm{Na}_{2} \mathrm{O}$ & 0,4 \\
$\mathrm{SiO}_{2}$ & 60,9 \\
$\mathrm{Fe}_{2} \mathrm{O}_{3}$ & 7,4 \\
$\mathrm{~K}_{2} \mathrm{O}$ & 3,4 \\
$\mathrm{Al}_{2} \mathrm{O}_{3}$ & 12,1 \\
\hline
\end{tabular}

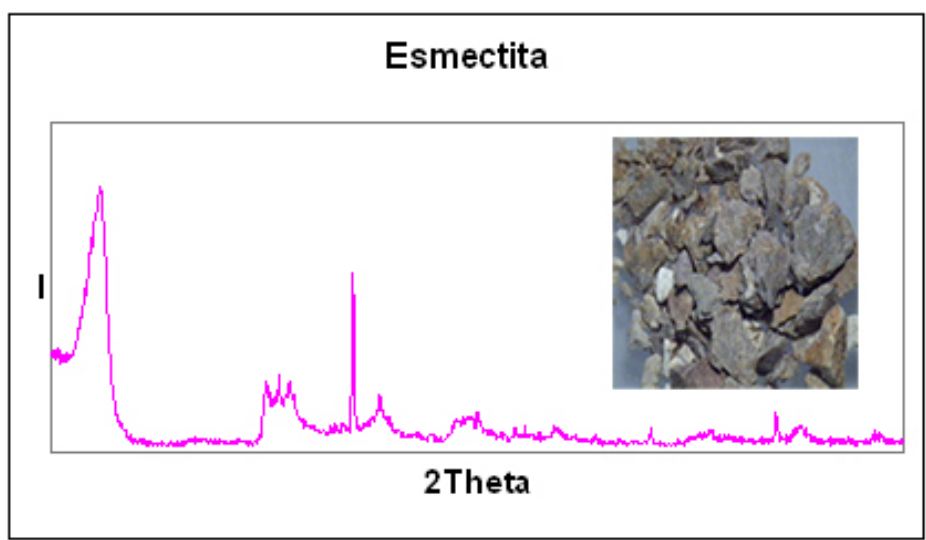

Figura 6 - Resultados obtidos no equipamento de difração de raios $X$ para amostra do argilomineral e foto do material estudado

Tabela 2 - Concentração de metal no líquido coletado no teste experimental

\begin{tabular}{|c|c|c|c|c|c|c|}
\hline \multirow[t]{2}{*}{ Célula } & \multicolumn{6}{|c|}{ Metal } \\
\hline & $\begin{array}{c}\mathrm{Cu} \\
(\mathrm{mg} / \mathrm{l})\end{array}$ & $\begin{array}{c}\mathrm{Mn} \\
(\mathrm{mg} / \mathrm{l})\end{array}$ & $\begin{array}{c}\mathrm{Fe} \\
(\mathrm{mg} / \mathrm{l})\end{array}$ & $\begin{array}{c}\mathrm{Pb} \\
(\mathrm{mg} / \mathrm{l})\end{array}$ & $\begin{array}{c}\mathrm{Cd} \\
(\mathrm{mg} / \mathrm{l})\end{array}$ & $\begin{array}{c}\mathrm{Zn} \\
(\mathrm{mg} / \mathrm{l})\end{array}$ \\
\hline $1 \mathrm{a}$ & nd & nd & 0,28 & 0,32 & 0,08 & nd \\
\hline $1 b$ & nd & nd & 0,16 & 0,24 & 0,06 & nd \\
\hline $2 \mathrm{a}$ & nd & nd & 0,39 & 0,74 & 3,03 & 3,91 \\
\hline $2 b$ & nd & 0,35 & 0,37 & 0,36 & 0,13 & nd \\
\hline $3 a$ & nd & 0,2 & 0,49 & 0,71 & 0,23 & 11,16 \\
\hline $3 b$ & nd & 0,01 & 0,56 & 1,13 & 1,2 & 499,8 \\
\hline $4 \mathrm{a}$ & nd & nd & 0,6 & 0,65 & 0,28 & 16,73 \\
\hline $4 b$ & nd & nd & 0,54 & 0,3 & 7,31 & 5,73 \\
\hline $5 \mathrm{a}$ & nd & 0,04 & 0,68 & 1,01 & 0 & 1601,4 \\
\hline $5 b$ & nd & 0,01 & 0,73 & 1,41 & 4,63 & 132,4 \\
\hline $6 a$ & nd & 0,02 & 0,7 & 0,77 & 2,71 & 196,35 \\
\hline $6 b$ & nd & 0,01 & 0,73 & 0,92 & 4,46 & 622,2 \\
\hline $6 c$ & nd & nd & 0,76 & 0,77 & 1,5 & 7,06 \\
\hline CONAMA 357/05 & 1 & 1 & 15 & 0,5 & 0,2 & 5 \\
\hline
\end{tabular}


Conforme comentado, após aproximadamente sessenta e dois dias de iniciado o experimento cessou o escoamento em todas as células. Foi observada então uma cimentação entre as camadas de resíduos da Cia. de Galvanoplastia (coloração avermelhada) e a escória da aciaria (coloração cinza). A célula 2, Figura 7, foi a que apresentou o tempo mais curto de cimentação. Na Figura 8 podemos observar os resultados, sob forma gráfica, apresentados na análise do percolado oriundo desta célula.

Os resultados apresentados indicam uma possibilidade de disposição que, com o tempo, poderia apresentar uma atenuação na mobilidade dos elementos potencialmente contaminantes, não só em função da capa de cimento formada, que restringiria a mobilidade, como também em função do argilomineral, que contribuiria, efetivamente, no processo. Conforme comentado acima, como o argilomineral estudado apresenta a característica de inchamento, isso contribui no processo retendo o líquido afluente no resíduo alcalino. Este resíduo, na célula 2, está disposto imediatamente acima do argilomineral. Esta característica de inchamento e redução de permeabilidade permite que o líquido permaneça por mais tempo no meio, provocando assim a cimentação em um período mais curto.

Portanto, em um primeiro momento, observa-se um resultado satisfatório, embora tenha havido ainda uma mobilidade de elementos deletérios, antes do bloqueio pela cimentação. Como a maioria dos solos desenvolvidos em ambiente tropical, dada a sua intensa lixiviação, apresenta uma composição química pobre em argilominerais, provavelmente, na situação real, o percolado pudesse atingir a algum corpo hídrico, até que a capa de cimento, por fim, se formasse, detendo o processo. Assim que, embora os resultados indiquem boas perspectivas de resolver dois problemas de disposição, quais sejam, dos resíduos provenientes do passivo ambiental da Ingá e dos oriundos do conversor da aciaria, são necessários novos esforços no sentido de aumentar a confiabilidade no processo. Desta forma, o prosseguimento do estudo deve trazer novos dados que auxiliarão na consecução deste objetivo. Naturalmente, seriam necessários estudos de novas formas de disposição, com alternância dos materiais em estudo, e mesmo com

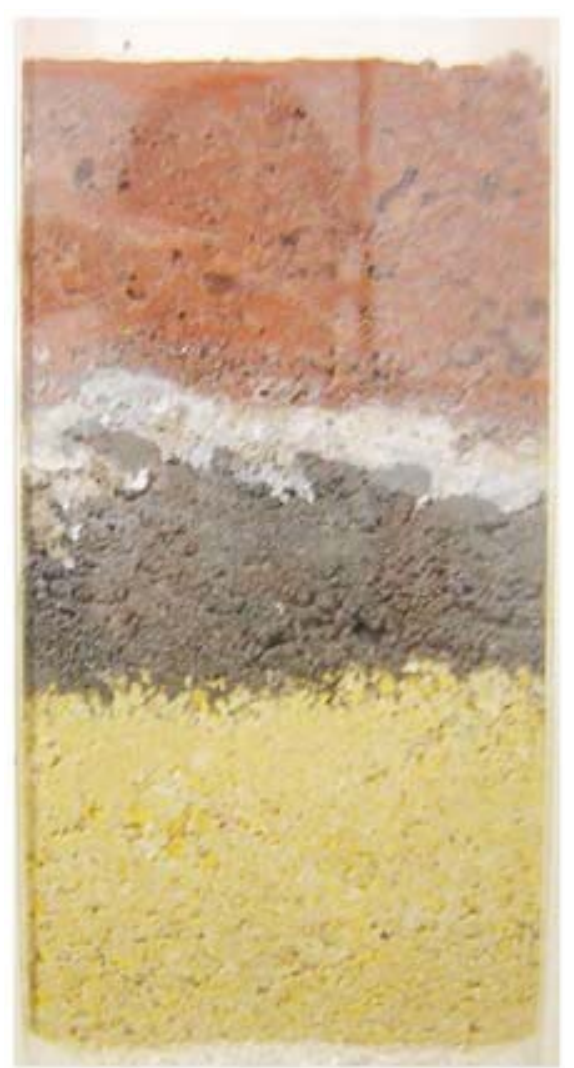

Figura 7 - Célula de acrílico (célula 2) apresentando cimentação (camada clara) entre os resíduos do passivo ambiental da Ingá e a escória de aciaria da Cia. Siderúrgica Nacional - CSN

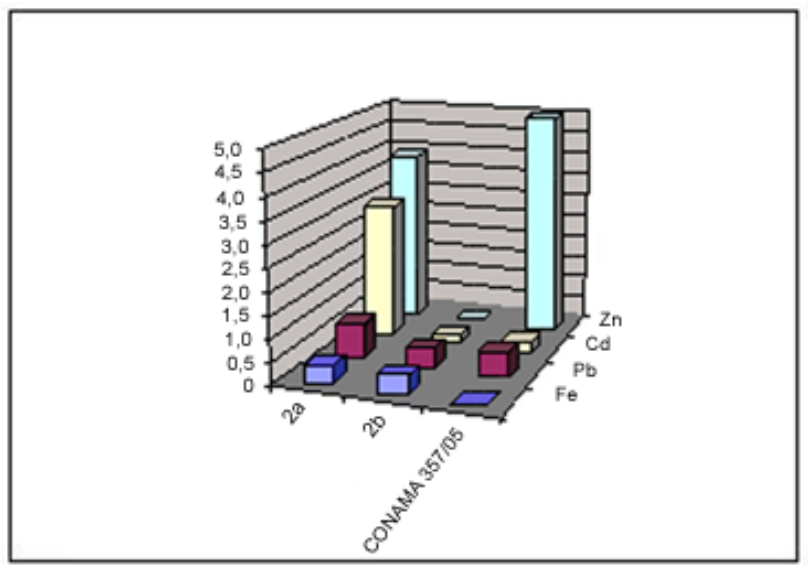

Figura 8 - Resultados das concentrações na célula 2 de elementos potencialmente contaminantes obtidos em análises realizadas com o equipamento de absorção atômica 
a mistura em proporções conhecidas dos resíduos, além, possivelmente, da inclusão de novos materiais sorventes de baixo custo. De todo modo, pode-se observar uma redução significativa na mobilidade dos elementos.

\section{CONCLUSÕES}

Com base no trabalho realizado, conclui-se que os resultados apresentados foram satisfatórios e indica que poderia ser tecnicamente viável a disposição escolhida. Os resultados esperados, a princípio, foram de que o resíduo contaminado fosse parcialmente inertizado pelo resíduo alcalino, imobilizando elementos deletérios, em associação com os argilominerais, estabelecendo assim uma relação funcional entre eles. Durante o estudo foi observado que a escória do processo de aciaria, quando acamado imediatamente abaixo do resíduo contaminado da Ingá, forma um cimento em relativamente pouco tempo na região de interface dos dois resíduos. Certamente o argilomineral disposto imediatamente abaixo do resíduo da CSN (a escória da aciaria) facilita o processo, devido a sua relativamente baixa permeabilidade. Portanto, a disposição apresentada pela célula 2 foi a que melhor resultado obteve, em função da cimentação ocorrida em tempo mais curto.

Quanto ao indicativo da viabilidade econômica pode-se considerar, a princípio, com boas perspectivas, devido a que já existe linha férrea ligando as duas regiōes. $\mathrm{O}$ porto de minérios se situa em Sepetiba, onde há também um grande pátio de materiais destinado às indústrias, conforme mencionado no corpo do trabalho. A demanda por soluções técnicas nesta região é grande, e o custo de operação pode ser relativamente baixo, devido à existência de infra-estrutura. No entanto, é necessária a utilização de alguma das metodologias existentes para a avaliação de impactos e dos custos ambientais. De qualquer forma, o estudo ora realizado poderá se tornar uma ferramenta útil nas tomadas de decisōes de destinação destes resíduos industriais, e em futuras destinaçôes de resíduos industriais de características similares.

\section{RECOMENDAÇÕES}

Evidentemente, estudos mais amplos haverão de contemplar, além de um processo de disposição dos resíduos eficiente, parâmetros mais adequados para que um conjunto de medidas, necessárias ao gerenciamento, se tornem factíveis.

No que se refere à disposição dos resíduos, o estudo da mistura em porcentagens diferenciadas, pode melhorar o desempenho do processo, conforme comentado anteriormente. Acreditase também que novos estudos devem aportar conhecimentos que permitam aumentar a eficiência, partindo-se dos desacordos revelados nas seis rodadas.

Por fim, deve-se ter em vista o estudo dos danos causados à população provenientes dos elementos deletérios já lixiviados do passivo ambiental nesses anos de disposição inadequada. Neste caso, são necessárias pesquisas, com aplicação de questionários de coleta de dados, que possam detectar os possíveis danos causados pelo excesso de elementos potencialmente contaminantes à população circunvizinha. Não existem, até o momento, estudos sistemáticos a esse respeito. Esta medida seria importante no cálculo dos custos ambientais e nos futuros projetos de recuperação da área.

\section{AGRADECIMENTOS}

Os autores gostariam de agradecer à FAPERJ pelo suporte financeiro, e à Escola Nacional de Saúde Pública ENSP/FIOCRUZ pelo apoio. Este trabalho fez parte do Programa de Pesquisa Estratégica, Desenvolvimento e Inovação - PED/ENSP. Ao Centro de Tecnologia Mineral - CETEM, pelo apoio nas análises. À Cia. Siderúrgica Nacional por fornecer o material e, em especial ao Dr. Luis Carlos Juroviski, gerente do setor de Meio Ambiente à época, pelo incentivo. Ao Laboratório de Difração de Raios X, da Universidade Federal Fluminense- LDRXUFF. Ao Instituto de Agronomia da Universidade Rural do Rio de Janeiro - UFRRJ, onde foram realizados os experimentos. A Maíra Matos e Walace Rodrigues da Silva, alunos do Centro Federal de Educação Tecnológica de Química de Nilópolis/RJ - CEFETq e bolsistas extracurricular da Escola Nacional de Saúde Pública - ENSP/ FIOCRUZ.

\section{REFERÊNCIAS}

ASSOCIAÇÃO BRASILEIRA DE NORMAS TÉCNICAS (ABNT). NBR 10004. Resíduos Sólidos-Classificação. Rio de Janeiro. 1987.
ASSOCIAÇÃO BRASILEIRA DE NORMAS TÉCNICAS (ABNT). NBR10005 Lixiviação de Resíduos Sólidos. Rio de Janeiro. 1987.

ASSOCIAÇÃO BRASILEIRA DE NORMAS TÉCNICAS (ABNT). NBR10006. Solubilização de Resíduos. Rio de Janeiro. 1987.

BERGAVA, F. \& LAGALY G. Surface modification of clay minerals. Applied Clay Science, 19, 1-3. 2001

BREWSTER M.D. \& PASSMORE R.J. Use of electrochemical ion generation for removing heavy metals from contaminated groundwater. Environmental Progress 13 (2), pp. 143-148. Abstract-Elsevier BIOBASE | Abstract + References in Scopus | Cited By in Scopus. 1994.

CONSELHO NACIONAL DE MEIO AMBIENTE. Resolução CONAMA 357 de 18/03/2005. Dispóe sobre classificação das águas. Disponível em http://www.mma.gov.br/port/ conama/res/res86/res2086.html. Acesso em 17/11/2006. 2005.

DAMASCENO, E.C. Disponibilidade, suprimento e demanda de minérios para a metalurgia. Série Estudo e Documentos. Ed. CETEM. 100p. http://www.cetem.gov.br/publicacao/cetem sed 69 p.pdf. 2006.

FARFÁN J.L.V. Bentonites as a material for a controlling contamination related to zinc hydrometallurgy, proceeding of the second international symposium on iron control in hydrometallurgy. Ottawa, Canadá. 565-579. 1996.

FEEMA. http://www.feema.rj.gov.br/baiasepetiba.asp?cat $=75$ (acesso em 7 de fevereiro de 2008)

FITCH, A.; SONG J.; STEIN J. Molecular structure effects on diffusion of cations in clays. Clays and Clays Minerals. 44 (3), 370-380. 1996.

FORSYTHE, W. Manual de laboratório de Física de Suelos. IICA. Costa Rica, 212p. 1975.

GRIFFIN, R. A. et al. Attenuation of pollutants in municipal landfill leachate by clay minerals: Heavy metal adsorption. Environmental Geology Notes, 79, 1 - 47. 1997.

KHALIL, C.M. \& TEIXEIRA L.C.F.L. Método analítico de determinação da capacidade de troca catiônica de argilominerais. In: II SEMINÁRIO DE QUÍMICA ANALÍTICA. CENPES, Rio de Janeiro, Brazil. 1992.

MARKUS J. \& KERTES A.S. Ion exchange and solvent extraction of metal complexes. Wiley, London (1969) 321-359. Markus and Kertes, 1969.

MYERS, N., R.A. et al. Biodiversity hotspots for conservation priorities. Nature 403: 853-845. 2000.

NASCIMENTO S.C.; HYPOLITO R.; RIBEIRO A.A. Disponibilidade de metais pesados em aterro de indústria siderúrgica. Revista Engenharia Sanitária e Ambiental.11 (3). 2006.

OLIVEIRA M.R.C. \& MARTINS J. Caracterização e classificação do resíduo sólido "pó do balão", gerado na indístria siderúrgica não integrada a carvão vegetal:- estudo de um caso na regiäo de Sete Lagoas/MG. Química Nova vol.26 (1). 2003.

PINHEIRO, R.S. Inertização de resíduo perigoso através do uso de resíduos industriais alcalinos. 
Tese de Mestrado. Instituto de Agronomia, Universidade Federal Rural do Rio de Janeiro, Brazil. 74 p. 2003.

REBHUN M. \& GALIL N. Wastewater treatment technologies. In: L. Zirm and J. Mayer, Editors, The Management of Hazardous Substances in the Environment, Elsevier Applied Science, London, New York. pp. 85-102. 1990.

ROCCA, A. A. C et al. Resíduos Sólidos Industriais. CETESB: São Paulo, 234 p. 1993.

SANTOS, P. S. Ciência e Tecnologia de Argilas. vol. 3, EDGARD BLUCHER, São Paulo. 1992

SRIVASTAVA S.K. et al. Studies on remove of some toxic metal ion part II (removal of lead and cadmium by montmorillonite and kaolinite). Environmental Technology Letters, 10: 275 - 282. 1989.

STANDARD METHODS FOR THE EXAMINATION OF WATER AND WASTEWATER. 20th ed., American Public Health Association/American Water Works Association/Water Environment Federation, Washington DC, USA. 1998

TORRES S. Barragem rompe e polui mangue em Itaguai (RJ). Fonte: Folha de São Paulo. DATA: 09/04/2003. http://www.koinonia.org.br/oq/ not contexto1.htm. 2003.

Endereço para correspondência:

Wilma de Carvalho Pereira

FIOCRUZ /ENSP

Escola Nacional de Saúde Pública

Rua Leopoldo Bulhões, 1480

Manguinhos

2 I 04 I-2 I 0 Rio de Janeiro - RJ

- Brasil

Tel.: (2 I) 2598-2569

E-mail: carvalho@ensp.fiocruz.br 